\title{
АПРОБАЦИЯ МОДИФИЦИРОВАННОГО (АГРЕГИРОВАННОГО) ПОКАЗАТЕЛЯ ОЦЕНКИ КОНКУРЕНТОСПОСОБНОСТИ РЕГИОНАЛЬНОГО ТУРИЗМА (НА ПРИМЕРЕ ИРКУТСКОЙ ОБЛАСТИ)
}

\author{
Н. Н. Даниленко, М. Ю. Ласси \\ Байкальский государственный университет, г. Иркутск, Российская Федерация
}

Информация о статье

Дата поступления

27 сентября 2017 г.

Дата принятия к печати 20 ноября 2017 г.

Дата онлайн-размещения 27 ноября 2017 г.

\section{Ключевые слова}

Региональный рынок туристских услуг; конкурентоспособность; методика оценки конкурентоспособности регионального туризма

\begin{abstract}
Аннотация
В настоящее время сорера внутреннего и въездного туризма Российской Федерации характеризуется значительным ростом конкуренции. В этой связи для любого регионального туристского рынка особую актуальность имеет вопрос оценки собственной конкурентоспособности. Однако анализ специальной экономической литературы свидетельствует об отсутствии единой общепринятой методики оценки конкурентоспособности регионального туризма. Настоящая статья посвящена апробации разработанной авторской методики оценки конкурентоспособности регионального туризма на примере Иркутской области с целью определения положений ее использования на уровне других регионов. На основе предложенной методики выявляются возможности и угрозы для сферы туризма данного региона, а также фракторы косвенного влияния, что позволяет обосновать целесообразность определенных направлений развития туризма. Доказывается возможность широкого использования данной методики для оценки конкурентоспособности регионального туризма, и определяются соответствующие условия для получения адекватного результата.
\end{abstract}

\section{TESTING OF THE MODIFIED (AGGREGATE) INDICATOR OF ASSESSMENT OF REGIONAL TOURISM COMPETITIVENESS (CASE STUDY OF IRKUTSK OBLAST)}

\author{
Nina N. Danilenko, Marina Yu. Lassi \\ Baikal State University, Irkutsk, Russian Federation
}

Article info

Received

September 27, 2017

Accepted

November 20, 2017

Available online

November 27, 2017

\section{Keywords}

Regional market of tourism services; competitiveness; technique of assessment of competitiveness of regional tourism

\begin{abstract}
Now the sphere of domestic and inbound tourism of the Russian Federation is characterized by significant growth in the competition. In this regard, the issue of assessment of its own competitiveness becomes vital for any regional tourism market. However, the analysis of special economic literature confirms lack of the uniform standard technique of assessment of regional tourism competitiveness. The present article is devoted to testing of the developed author's technique of assessment of regional tourism competitiveness (case study of Irkutsk Oblast) for the purpose of its use in other regions. Based on the offered technique, opportunities and threats for the sphere of tourism of this region as well as the factors of indirect influence come to light that allow proving expediency of certain directions of tourism development. The authors prove the possibility of wide use of this technique for assessment of competitiveness of regional tourism market and describe the corresponding conditions for obtaining a sound result.
\end{abstract}


Введение. Мировой рынок туристских услуг в течение нескольких последних лет продолжает неуклонно расти (около 4 \% в год - по данным Всемирной туристской организации), что способствует появлению новых рабочих мест и повышению благосостояния общества во многих регионах мира. Однако благотворное влияние развития туризма на мировую экономику сопровождается значительным усилением конкурентной борьбы как среди национальных туристских рынков, так и среди региональных рынков туризма одного и того же государства.

С этой позиции особый интерес представляет туристский рынок Российской Федерации как один из наиболее динамично развивающихся туристских рынков, но при этом недостаточно изученный в региональном аспекте. Так, по данным Росстата, Россия с 2016 г. входит в топ-10 стран по уровню въездного туризма', ежегодно увеличивая показатели по данному направлению. Также в последние годы наблюдается неуклонный рост доли внутреннего туризма (в 2016 г. на $18 \%)$ и значительное сокращение доли выездного туризма (в 2016 г. на $20 \%)^{2}$. При этом изменяется и сегментация туристского рынка России: отмечается уменьшение числа туроператоров, специализирующихся на выездном туризме (с 2500 ед. в 2014 г. до 750 ед. в 2016 г.), и существенное увеличение числа туроператоров в сегменте внутреннего и въездного туризма (с 700 ед. в 2014 г. до 3700 ед. в 2016 г.) $)^{3}$.

Закономерным следствием отмеченных тенденций в сорере туризма Российской Федерации является значительное усиление конкуренции не только среди отдельных туристских компаний, специализирующихся на въездном и внутреннем туризме, но и среди целых региональных туристских рынков. В этой связи для любого региона РФ особенно актуальным становится исследование собственных конкурентных преимуществ и угроз конкурентоспособности. При этом успех того или иного регионального туристского рынка во многом зависит от своевременности проведения данных исследований и их объективности. Первоочередным шагом в этом направлении будет правильный выбор инструментов исследования и методики

Динамика спроса на туристские услуги в России // Бюллетень о текущих тенденциях российской экономики. 2016. № 19. URL: http://ac.gov.ru/files/ publication/a/11063.pdf.

2 Главным открытием года будет Египет. URL: https: / / www.gazeta.ru/business /2016/12/29/10455245. shtml.

$$
{ }^{3} \text { Там же. }
$$

оценки конкурентоспособности туристского рынка определенного уровня. И если на национальном уровне общепринятые методики оценки туризма существуют, то применительно к региональному уровню их практически нет. Поэтому вопрос разработки и апробации соответствующей методики оценки конкурентоспособности регионального туризма является несомненно актуальным.

Постановка проблемы. Проблема заключается в разработке и адекватной апробации методики оценки конкурентоспособности регионального туризма на примере Иркутской области с целью выявления возможности ее использования на уровне других регионов, что позволит внести вклад в решение научного вопроса создания единой общепринятой методики оценки конкурентоспособности регионального туризма и в решение практической задачи повышения его конкурентоспособности.

Методика исследования. Информация для осуществления данной работы была получена путем анкетирования и интервьюирования специалистов сфреры регионального туризма, а также на основании изучения специализированной литературы, информации с веб-сайтов федеральных и муниципальных органов власти, данных статистических сборников.

Степень разработанности проблемы. Вопрос оценки конкурентоспособности туризма на национальном уровне является достаточно проработанным: имеется большое количество исследований, посвященных оценке конкурентоспособности национального туризма [1-4]; четко определены методика и используемые показатели оценки (Tourism competitiveness index). Однако вопрос оценки конкурентоспособности регионального туризма находится в стадии становления. Основная сложность его разработки заключается в выборе соответствующего показателя оценки, что предполагает изучение накопленного научного и практического опыта в сфере национального и регионального туризма.

Комплексный анализ существующих в отечественной и зарубежной практике подходов к оценке конкурентоспособности туризма, проведенный М. Ю. Ласси под руководством Н. Н. Даниленко, позволил выявить их недостатки и достоинства с позиции практического использования на региональном уровне [5]. Анализ показал, что такие подходы имеют достаточно диффреренцированный характер используемых показателей и методов количественного измерения данных, что в ряде случаев при- 
водит к несопоставимости конечных результатов и затрудняет сравнительную оценку конкурентоспособности регионального туризма. Был сделан вывод, что для получения объективных и сопоставимых результатов необходимо разработать рациональную методику оценки конкурентоспособности регионального туризма, которую можно будет единообразно использовать применительно ко всем регионам России.
В рамках решения данной проблемы М. Ю. Ласси был предложен модифицированный (агрегированный) показатель для оценки конкурентоспособности регионального туризма - индекс конкурентоспособности регионального туризма, основой для расчета которого послужил Tourism competitiveness index - показатель, широко используемый для оценки конкурентоспособности национального туризма (табл. 1).

\section{Перечень применяемых показателей для оценки индекса конкурентоспособности регионального туризма}

\begin{tabular}{|c|c|}
\hline Элемент & Показатели \\
\hline \multicolumn{2}{|r|}{ Нормативно-правовая база } \\
\hline \multirow{2}{*}{ Политические правила } & Уровень прямых иностранных инвестиций в развитие туризма региона \\
\hline & Доступность получения визы для иностранных граждан \\
\hline \multirow{2}{*}{$\begin{array}{l}\text { Устойчивость } \\
\text { окружающей среды }\end{array}$} & Наличие исследований о влиянии туризма на окружающую среду \\
\hline & Уровень опасных выбросов в окружающую среду \\
\hline \multirow{3}{*}{$\begin{array}{l}\text { Охрана } \\
\text { и безопасность }\end{array}$} & Уровень преступности в регионе \\
\hline & Уровень дорожно-транспортных происшествий в регионе \\
\hline & Вероятность возникновения природных катастроф в регионе \\
\hline \multirow{2}{*}{ Гигиена и здоровье } & $\begin{array}{l}\text { Территориальная удаленность медицинских учреждений от основных туристских } \\
\text { объектов региона }\end{array}$ \\
\hline & Количество врачей и больничных коек \\
\hline $\begin{array}{l}\text { Приоритетность } \\
\text { сореры путешествий } \\
\text { и туризма }\end{array}$ & $\begin{array}{l}\text { Наличие государственных и региональных налоговых льгот и субсидий для бизнеса в } \\
\text { сфере туризма }\end{array}$ \\
\hline \multicolumn{2}{|r|}{ Бизнес-среда и инфраструктура } \\
\hline \multirow{2}{*}{$\begin{array}{l}\text { Инфраструктура воз- } \\
\text { душного транспорта }\end{array}$} & Количество внутренних и международных рейсов \\
\hline & Качество аэропортов в регионе \\
\hline \multirow{4}{*}{$\begin{array}{l}\text { Инфраструктура } \\
\text { наземного транспорта }\end{array}$} & Качество автомобильных дорог \\
\hline & Качество услуг железнодорожного транспорта \\
\hline & Качество услуг водного транспорта \\
\hline & Плотность транспортных сетей в регионе \\
\hline \multirow{4}{*}{$\begin{array}{l}\text { Туристская } \\
\text { инфрраструктура }\end{array}$} & Количество номерного фонда \\
\hline & Количество предприятий питания \\
\hline & Количество санитарных узлов вблизи основных туристских объектов \\
\hline & Количество банкоматов и обменных пунктов \\
\hline \multirow{2}{*}{$\begin{array}{l}\text { Информацион- } \\
\text { но-коммуникационная } \\
\text { инфраструктура }\end{array}$} & Степень оснащенности Интернетом объектов туристской инфрраструктуры \\
\hline & Количество туристско-информационных центров в регионе \\
\hline \multirow{4}{*}{$\begin{array}{l}\text { Ценовая конкуренто- } \\
\text { способность в туриз- } \\
\text { ме и путешествиях }\end{array}$} & Уровень цен на авиабилеты до региона назначения \\
\hline & Уровень цен на железнодорожные билеты до региона назначения \\
\hline & Уровень цен на услуги автомобильного транспорта внутри региона \\
\hline & Уровень цен на размещение внутри региона \\
\hline \multicolumn{2}{|r|}{ Человеческие, природные и культурные ресурсы } \\
\hline $\begin{array}{l}\text { Человеческие } \\
\text { ресурсы }\end{array}$ & Уровень профессиональной подготовки сотрудников индустрии туризма \\
\hline \multirow{4}{*}{$\begin{array}{l}\text { Привлекательность } \\
\text { туризма и путеше- } \\
\text { ствий }\end{array}$} & Взаимоотношения туристов с местным населением \\
\hline & Популярность региона у туристов (по количеству ночевок) \\
\hline & Частота повторных посещений региона \\
\hline & Продолжительность туристского сезона в регионе \\
\hline \multirow{2}{*}{ Природные ресурсы } & Богатство флоры и фауны \\
\hline & Количество памятников природы в регионе \\
\hline Культурные ресурсы & Количество памятников культуры в регионе \\
\hline
\end{tabular}


Для оценки качественных показателей предлагалось анкетирование и интервьюирование региональных специалистов туристской индустрии, что представляется известным и доступным методом исследования. Обработка полученных данных предусматривала использование равномерной шкалы от 1 (самое низкое качество) до 5 (самое высокое качество).

Источником количественных данных послужили статистическая информация и результать ранее проводившихся исследований, посвященных региональному туризму. В целях унифрикации сравнения обработка полученных количественных данных предусматривала применение следующей формулы:

$$
I_{k}=4 \cdot\left(\frac{x_{i}-x_{\min }}{x_{\text {max }}-x_{\min }}\right)+1,
$$

где $I_{k}$ - единичный индекс конкурентоспособности по і-му показателю за отчетный период, ед.; $x_{i}$ - величина $i$-го показателя за отчетный период, ед.; $x_{\min }$ - наименьшая величина i-го показателя за изучаемый период исследования, ед.; $x_{\max }$ - наибольшая величина i-го показателя за изучаемый период исследования, ед.

Заключительным этапом оценки конкурентоспособности регионального туризма явилось определение среднего индекса конкурентоспособности для каждого из 14 элементов посредством арифметического усреднения нормализованных количественных показателей и упорядоченных качественных показателей в соответствии с равномерной шкалой. На основании результатов данной операции был получен средний индекс конкурентоспособности для каждой из трех групп элементов и определен итоговый индекс конкурентоспособности регионального рынка туристских услуг [6, с. 174].

Проведенное исследование показало, что разработка модифицированного (агрегированного) показателя оценки регионального туризма возможна.

Практическое использование данного показателя предполагает его апробацию, которая была осуществлена на примере рынка туризма Иркутской области как региона, обладающего колоссальным туристским потенциалом и при этом имеющего определенные проблемы, сдерживающие его развитие. Так, согласно Национальному туристическому рейтингу привлекательности регионов РФ для туристов, в 2015 г. Иркутская область находилась на 36-м месте, занимая средние позиции рейтинга ${ }^{4}$. Эксперты связывали столь невысокие показатели туристской привлекательности при «колоссальном» туристском потенциале региона с удаленностью данного региона от основных транспортных узлов (Москвы и Санкт-Петербурга), высокими ценами на билеты, непростой криминогенной ситуацией и недостаточной развитостью инфраструктуры 5 . Однако уже в 2016 г. ситуация с туристской привлекательностью региона значительно изменилась. По данным Национального туристического рейтинга 2016 г., Иркутская область оказалась в первой двадцатке регионов по туристской привлекательности, заняв 15-е место с общим баллом 62,4. Исходя из этого, можно предположить, что за один календарный год отмеченные экспертами проблемы туристской сферы в данном регионе вряд ли могли исчезнуть или в других регионах значительно усугубиться, что в конечном итоге столь сильно отразилось бы на результате туристской привлекательности. И если стоимость билетов и криминогенная ситуация действительно могли существенно измениться, то, например, активное развитие туристской инфрраструктуры в Иркутской области в течение одного года маловероятно. Не изменилась и удаленность региона от основных транспортных узлов. Между тем результаты рейтинга свидетельствуют ○ влиянии на привлекательность региона для туристов других, ранее не выявленных факторов и, как следствие, об изменении его конкурентного статуса на национальном туристском рынке.

Таким образом, целью настоящего исследования явилась апробация разработанной методики оценки конкурентоспособности туризма на примере Иркутской области и выявление степени влияния каждой из групп элементов оценки на общую конкурентоспособность регионального туризма, что будет служить подтверждением возможности решения вопроса создания единой общепринятой методики оценки конкурентоспособности регионального туризма.

Процесс изучения проблемы. Для оценки качественных критериев индекса конкурентоспособности регионального туризма были привлечены восемь экспертов, имеющих опыт профессиональной деятельности в сорере рекреации и туризма более пяти лет. Один из экспертов на момент проведения исследования занимал руководящую

${ }^{4}$ Национальный туристический рейтинг (№ 1). URL: http://russia-rating.ru/info/9857.html.

${ }^{5}$ Там же. 
должность в государственных органах, регулирующих деятельность туризма в Иркутской области. Исследование проводилось посредством применения 5-балльной шкалы, где 1 - очень плохое состояние оцениваемого показателя; 2 - неудовлетворительное; 3 - удовлетворительное; 4 - хорошее; 5 - отличное.
Источником информации для оценки количественных элементов оценки конкурентоспособности регионального туризма в Иркутской области стали статистические данные, ежегодно публикуемые Росстатом, а также данные региональных министерств и ведомств. Основные результаты исследования представлены в табл. 2.

Таблица 2

Соответствующие результаты оценки показателей состояния конкурентоспособности туризма Иркутской области в 2014-2016 гг.

\begin{tabular}{|c|c|c|c|c|c|}
\hline Элемент & Показатели & 2014 & 2015 & 2016 & Среднее \\
\hline \multicolumn{2}{|r|}{ Нормативно-правовая база } & 3,0 & 2,8 & 2,7 & 2,8 \\
\hline \multirow[t]{2}{*}{$\begin{array}{l}\text { Политические } \\
\text { правила }\end{array}$} & $\begin{array}{l}\text { Уровень прямых иностранных инвестиций в развитие туризма } \\
\text { региона }\end{array}$ & 2,6 & 2,8 & 3,1 & \multirow[t]{2}{*}{3,5} \\
\hline & Доступность получения визы для иностранных граждан & 4,1 & 4,3 & 4,4 & \\
\hline \multirow{2}{*}{$\begin{array}{l}\text { Устойчивость } \\
\text { окружающей } \\
\text { среды }\end{array}$} & $\begin{array}{l}\text { Наличие исследований о влиянии туризма на окружающую } \\
\text { среду }\end{array}$ & 2,9 & 3,1 & 3,4 & \multirow[t]{2}{*}{2,1} \\
\hline & Уровень опасных выбросов в окружающую среду & 5,0 & 3,4 & 1,0 & \\
\hline \multirow{3}{*}{$\begin{array}{l}\text { Охрана } \\
\text { и безопасность }\end{array}$} & Уровень преступности в регионе & 1,2 & 1,0 & 5,0 & \multirow{3}{*}{2,6} \\
\hline & Уровень дорожно-транспортных происшествий в регионе & 2,0 & 5,0 & 1,0 & \\
\hline & Вероятность возникновения природных катастроф в регионе & 2,6 & 2,5 & 2,9 & \\
\hline \multirow[t]{2}{*}{$\begin{array}{l}\text { Гигиена } \\
\text { и здоровье }\end{array}$} & $\begin{array}{l}\text { Территориальная удаленность медицинских учреждений от } \\
\text { основных туристских объектов региона }\end{array}$ & 2,4 & 2,5 & 2,5 & \multirow[t]{2}{*}{2,5} \\
\hline & Количество врачей и больничных коек & 5,0 & 1,1 & 1,8 & \\
\hline $\begin{array}{l}\text { Приоритет- } \\
\text { ность сореры } \\
\text { путешествий } \\
\text { и туризма }\end{array}$ & $\begin{array}{l}\text { Наличие государственных и региональных налоговых льгот и } \\
\text { субсидий для бизнеса в сфрере туризма }\end{array}$ & 2,1 & 2,1 & 2,1 & 2,1 \\
\hline \multicolumn{2}{|r|}{ Бизнес-среда и инфрраструктура } & 3,4 & 3,5 & 3,3 & 3,4 \\
\hline \multirow{2}{*}{$\begin{array}{l}\text { Инфраструкту- } \\
\text { ра воздушного } \\
\text { транспорта }\end{array}$} & Количество внутренних и международных рейсов & 3,8 & 4,1 & 4,3 & \multirow{2}{*}{3,7} \\
\hline & Качество аэропортов в регионе & 3,3 & 3,4 & 3,4 & \\
\hline \multirow{4}{*}{$\begin{array}{l}\text { Инфрраструкту- } \\
\text { ра наземного } \\
\text { транспорта }\end{array}$} & Качество автомобильных дорог & 2,4 & 2,9 & 3,3 & \multirow{4}{*}{3,5} \\
\hline & Качество услуг железнодорожного транспорта & 3,9 & 4,0 & 4,0 & \\
\hline & Качество услуг водного транспорта & 3,4 & 3,4 & 3,4 & \\
\hline & Плотность транспортных сетей в регионе & 3,6 & 3,6 & 3,8 & \\
\hline \multirow{4}{*}{$\begin{array}{l}\text { Туристская } \\
\text { инораструк- } \\
\text { тура }\end{array}$} & Количество номерного фонда & 5,0 & 4,4 & 1,0 & \multirow{4}{*}{3,3} \\
\hline & Количество предприятий питания & 3,9 & 4,0 & 4,1 & \\
\hline & $\begin{array}{l}\text { Количество санитарных узлов вблизи основных туристских } \\
\text { объектов }\end{array}$ & 2,4 & 2,5 & 2,6 & \\
\hline & Количество банкоматов и обменных пунктов & 3,0 & 3,5 & 3,6 & \\
\hline \multirow{2}{*}{$\begin{array}{l}\text { Инфоормаци- } \\
\text { онно-комму- } \\
\text { никационная } \\
\text { инфраструк- } \\
\text { тура }\end{array}$} & $\begin{array}{l}\text { Степень оснащенности Интернетом объектов туристской } \\
\text { инфрраструктуры }\end{array}$ & 3,3 & 3,8 & 4,0 & \multirow[b]{2}{*}{3,6} \\
\hline & Количество туристско-информационных центров в регионе & 3,3 & 3,6 & 3,8 & \\
\hline \multirow{4}{*}{$\begin{array}{l}\text { Ценовая } \\
\text { конкуренто- } \\
\text { способность в } \\
\text { туризме } \\
\text { и путешествиях }\end{array}$} & Уровень цен на авиабилеты до региона назначения & 2,5 & 2,5 & 2,4 & \multirow{4}{*}{3,0} \\
\hline & $\begin{array}{l}\text { Уровень цен на железнодорожные билеты до региона } \\
\text { назначения }\end{array}$ & 3,0 & 2,9 & 2,9 & \\
\hline & $\begin{array}{l}\text { Уровень цен на услуги автомобильного транспорта внутри } \\
\text { региона }\end{array}$ & 3,8 & 3,4 & 3,4 & \\
\hline & Уровень цен на размещение внутри региона & 3,4 & 3,4 & 3,0 & \\
\hline \multicolumn{2}{|r|}{ Человеческие, природные и культурные ресурсы } & 3,3 & 3,7 & 4,0 & 3,7 \\
\hline $\begin{array}{l}\text { Человеческие } \\
\text { ресурсы }\end{array}$ & $\begin{array}{l}\text { Уровень профрессиональной подготовки сотрудников } \\
\text { индустрии туризма }\end{array}$ & 2,8 & 2,9 & 2,9 & 2,8 \\
\hline
\end{tabular}




\begin{tabular}{|c|c|c|c|c|c|}
\hline Элемент & Показатели & 2014 & 2015 & 2016 & Среднее \\
\hline \multirow{4}{*}{$\begin{array}{l}\text { Привлекатель- } \\
\text { ность туризма } \\
\text { и путешествий }\end{array}$} & Взаимоотношения туристов с местным населением & 3,4 & 3,6 & 3,8 & \multirow{4}{*}{3,1} \\
\hline & Популярность региона у туристов (по количеству ночевок) & 1,0 & 2,9 & 5,0 & \\
\hline & Частота повторных посещений региона & 3,3 & 3,5 & 4,0 & \\
\hline & Продолжительность туристского сезона в регионе & 2,3 & 2,5 & 2,6 & \\
\hline \multirow{2}{*}{$\begin{array}{l}\text { Природные } \\
\text { ресурсы }\end{array}$} & Богатство фрлоры и фрауны & 5,0 & 5,0 & 5,0 & \multirow{2}{*}{4,7} \\
\hline & Количество памятников природы в регионе & 4,9 & 4,9 & 4,9 & \\
\hline $\begin{array}{l}\text { Культурные } \\
\text { ресурсы }\end{array}$ & Количество памятников культуры в регионе & 4,3 & 4,3 & 4,3 & 4,3 \\
\hline \multicolumn{2}{|c|}{ Общая конкурентоспособность } & 3,2 & 3,3 & 3,3 & 3,3 \\
\hline
\end{tabular}

В рамках нормативно-правовой базы элемент оценки «политические правила» представлен такими показателями, как уровень прямых иностранных инвестиций в развитие туризма региона и доступность получения визы для иностранных граждан. По данному элементу Иркутская область характеризуется средними результатами конкурентоспособности (средний балл - 3,5). Невысокий уровень иностранных инвестиций в туризм региона, наблюдаемый в течение трех последних лет, компенсируется высоким уровнем открытости нашего государства для иностранных туристов, что может являться косвенной причиной роста въездного туризма в регионе в настоящее время. При этом значение каждого из показателей ежегодно повышается, что, несомненно, оказывает положительное воздействие на весь элемент оценки «политические правила».

На конкурентоспособность туризма Иркутской области существенно влияет устойчивость окружающей среды (средний балл $2,1)$. Уровень опасных выбросов ежегодно растет, что угрожает региону не только с позиции туристского бренда, в основу которого положено озеро Байкал как самое чистое озеро планеты, но и с позиции общего качества жизни и здоровья местного населения. При этом особый интерес в научных обсуждениях представляет гипотеза о «замкнутости» данной проблемы на туризм: рост туризма $=$ экономический рост региона = рост опасных выбросов в окружающую среду региона; спад туризма $=$ спад в экономике региона $=$ снижение опасных выбросов в окружающую среду. Поиск оптимального решения этой проблемы способствует ежегодному увеличению числа научных исследований в области охраны окружающей среды на региональном уровне. Последнее, разумеется, оказывает положительное влияние на конкурентоспособность туризма Иркутской области, что выражается в повышении оценки по данному критерию с 2,9 до 3,4 балла.
Также один из наихудших результатов (средний балл $-2,6$ ) в общей конкурентоспособности региона имеет элемент оценки «охрана и безопасность», представленный такими показателями, как уровень преступности, уровень дорожно-транспортных происшествий и вероятность возникновения природных катастрофр. Оценка конкурентоспособности туризма по данному элементу совпала с мнением экспертов Национального туристического рейтинга, считающих высокий уровень преступности в регионе одной из главных проблем туризма в Иркутской области. При этом, как показывают данные социологических опросов, публикуемых на различных тематических туристских сайтах, для туристов безопасность - одно из наиболее значимых условий выбора того или иного региона в целях отдыха. Эксперты, участвовавшие в опросе, в качестве основной причины столь низких показателей оценки по данному элементу называют пресловутый человеческий фактор, имеющий как прямое влияние на безопасность туристов (уровень преступности и уровень дорожно-транспортных происшествий), так и косвенное (лесные пожары, происходящие по вине человека, как фактор возникновения природных катастрофр в регионе).

Подгруппа критериев «гигиена и здоровье» тоже по результатам исследования имеет неудовлетворительную оценку (средний балл - 2,5). Между тем достаточно сложно быть туристически развитым регионом, на звание которого могла бы претендовать Иркутская область, при отсутствии качественной и доступной медицинской помощи.

Развитию туризма в Иркутской области государственные $и$ региональные власти уделяют недостаточное внимание, о чем свидетельствуют результаты оценки элемента конкурентоспособности «пиоритетность сфреры путешествий и туризма» (средний балл - 2,1). Так, по мнению экспертов, участвовавших в исследовании, одним из 
сдерживающих развитие регионального туризма факторов является отсутствие экономической поддержки бизнеса со стороны государства, наблюдаемое в целом по стране. Например, в Иркутской области единственным действующим в рамках программы поддержки и развития туристского бизнеса региона является проект «Особая экономическая зона туристско-рекреационного типа «Ворота Байкала», созданный в 2005 г. За 11 лет существования, ввиду отсутствия специализированного продвижения в бизнес-кругах и достаточной фринансовой поддержки со стороны государственной и региональной власти, резидентами данного проекта стали только шесть организаций. При этом заметное развитие получил лишь один из них - горнолыжный курорт «Гора Соболиная», что в том числе указывает на низкую эфффективность проекта. С сентября 2016 г. «Ворота Байкала» переданы в управление правительства Иркутской области, что по прогнозам экспертов должно было поспособствовать «активизации работы» над проектом 6 . Однако на данный момент оценить эфффективность работ не представляется возможным по причине отсутствия их как таковых (исключение составляет курорт «Гора Соболиная»).

Однойиз наиболее многочисленных групп элементов является группа «бизнес-среда и инфрраструктура», представленная такими составляющими, как ценовая конкурентоспособность в туризме и путешествиях, инфраструктура воздушного и наземного транспорта, информационно-коммуникационная инфраструктура и отдельно туристская инфраструктура. Конкурентоспособность Иркутской области по данным элементам оценки, вопреки мнению экспертов Национального туристического рейтинга, находится не в столь удручающем состоянии и получает удовлетворительную оценку в общей конкурентоспособности региона (средний балл - 3,4). Так, наиболее благоприятно в регионе складывается ситуация с инфраструктурой воздушного транспорта (средний балл - 3,7), с качеством услуг железнодорожного транспорта (средний балл - 4,0) и количеством предприятий питания (средний балл - 4,0). При этом имеются определенные вопросы относительно качества автомобильных дорог в регионе (что является достаточно распространенной проблемой на всей территории России) и количества санитарных узлов вблизи основных туристских

6 Особая экономическая зона «Ворота Байкала». URL: http: //baikal-sez.ru/about/history. объектов. Данные показатели характеризуются одними из самых низких оценок в общей конкурентоспособности туризма региона по направлению «инфраструктура» (средние баллы - 2,9 и 2,5). Особенно парадоксальной выглядит оценка конкурентоспособности Иркутской области по такому критерию, как количество номерного фонда: несмотря на значительный рост числа туристов в регионе в последние несколько лет, количество номерного фонда ежегодно снижается, что в итоге не самым лучшим образом влияет на конкурентоспособность региона по данному критерию (средний балл - 3,5). Однако необходимо отметить, что, за исключением данного критерия, по всем остальным видам инфраструктуры конкурентоспособность туризма региона с каждым годом повышается или остается на прежнем уровне, что свидетельствует о положительной динамике развития соеры туризма.

Отрицательная динамика наблюдается в ценовой конкурентоспособности туризма Иркутской области. За последние три года наряду с ростом туристского потока в регионе значительно возросли и цены на услуги размещения. При этом, как отмечают эксперты, уровень сервиса снизился или не изменился. Также огромным камнем преткновения для туристов, решивших посетить Иркутскую область, становятся очень высокие и зачастую ничем не регламентированные цены на авиаи железнодорожные билеты до Иркутска7. Результатом подобной ценовой неконкурентоспособности для региона могут стать значительные потери туристского потока в сегменте въездного туризма и очередная переориентация внутреннего сегмента на выездной.

Проблема недостаточного качества сервиса на предприятиях сореры туризма региона традиционно тесно связана с проблемой низкого уровня профессиональной подготовки специалистов для данной сферы. Так, конкурентоспособность Иркутской области по этому элементу оценивается всего в 2,8 балла, что эквивалентно оценке «неудовлетворительно». При этом, как отмечают эксперты, отсутствие элементарных профессиональных знаний характерно для всех уровней сотрудников туристской сореры - от обслуживающего персонала до топ-менеджмента.

Благоприятной тенденцией для Иркутской области является рост ее конкурентоспособности по такому элементу, как

7 Слишком дорого. URL: http://baikal-info.ru/ friday /2013/23/004003.html. 
«привлекательность туризма и путешествий» (с 2,5 балла в 2014 г. до 3,8 балла в 2016 г.). Помимо ранее указанного значительного роста туристского потока на территории Иркутской области ежегодно увеличивается и число повторных посещений региона, что говорит об общем повышении уровня удовлетворенности туристов отдыхом на территории региона. Слабым звеном элемента «привлекательность туризма и путешествий» до сих пор остается малая продолжительность туристского сезона в Иркутской области (средний балл - 2,5). Однако если еще несколько лет назад представители туристского бизнеса принимали это как данность, фактически работая по два-три месяца в году, то на сегодняшний день ими предпринимаются активные и небезуспешные попытки сглаживания сезонности. Яркий пример горнолыжный курорт «Гора Соболиная», считающийся одним из лучших горнолыжных курортов России, ежегодно привлекающий тысячи туристов со всей страны и из-за рубежа на свои склоны с ноября по конец апреля и успешно реализующий программы детского отдыха в летний период.

Наиболее сильной стороной конкурентоспособности туризма Иркутской области являются ее культурные и природные ресурсы, оцененные экспертами в 4,3 балла и 4,7 балла в общей конкурентоспособности региона за последние три года. Живописнейшие природные ландшафты, богатейшее разнообразие животного и растительного мира, уникальное культурно-историческое наследие, первозданная красота величественной дикой природы и кристальная чистота признанной жемчужины Сибири озера Байкал рассматриваются одним из главных конкурентных преимуществ региона как на национальном, так и на мировом рынках туризма и обусловливают его колоссальный туристский потенциал.

Так, несмотря на значительное снижение конкурентоспособности туризма Иркутской области в 2014-2016 гг. по группам элементов «нормативно-правовая база» и «бизнес-среда и инфраструктура», общая конкурентоспособность туризма региона за последние три года незначительно возросла, что свидетельствует о ключевом влиянии на общий результат исследования группы элементов «человеческие, природные и культурные ресурсы».

Обсуждение. Апробация модифицированного (агрегированного) показателя для оценки конкурентоспособности регионального туризма - индекса конкурентоспособ- ности регионального туризма - на примере Иркутской области доказала возможность, целесообразность и высокую результативность его использования для оценки любого регионального туристского рынка. Отмеченное положение во многом объясняется применением в рамках данного показателя широкого спектра элементов оценки, позволяющих составить комплексное представление о конкурентоспособности туризма в изучаемом регионе и выявить существующие возможности и угрозы, а также фракторы косвенного влияния. Используемый перечень элементов оценки, на наш взгляд, является базовым и минимально необходимым для осуществления объективной оценки конкурентоспособности туризма изучаемого региона, поскольку помимо обстоятельного изучения регионального туризма позволяет исследовать и степень воздействия на туризм смежных сорер (здравоохранение, охрана окружающей среды, безопасность и т. д.).

Также необходимо отметить универсальность и доступность методов сбора и обработки данных, применяемых в рамках данного показателя (статистические данные, социологический опрос и интервьюирование), что позволяет проводить исследование конкурентоспособности туризма на любых региональных рынках. Единственным необходимым условием для этого должна быть доступность для исследователя общих ежегодных социально-экономических данных, публикуемых региональными органами статистики и позволяющих оценить динамику и направленность изменений конкурентного статуса туризма региона по представленным количественным данным. Важным положением данного вопроса является своевременность получения такой информации. Например, в соседней с Иркутской областью Республике Бурятия статистические данные за 2016 г. будут представлены лишь в конце текущего, 2017 года, что создает определенный временной лаг для исследования и оценки конкурентоспособности туризма данного региона и не лучшим образом влияет на своевременность разработки и принятия соответствующих управленческих решений по результатам исследования.

Однако при апробации индекса конкурентоспособности регионального туризма на примере Иркутской области необходимые статистические данные были получены своевременно и в должном объеме, что позволило оперативно оценить конкурентоспособность туризма региона и сделать определенные выводы. Так, результаты 
исследования показали, что эфрфективную реализацию туристского потенциала Иркутской области существенно осложняет ряд выявленных проблем, актуальных для региона на протяжении нескольких последних лет: низкая устойчивость окружающей среды (2,1 балла), проблемы с охраной и безопасностью (2,6 балла) и гигиеной и здоровьем (2,5 балла), крайне низкая приоритетность сореры путешествий и туризма для региональной и государственной власти (2,1 балла), а также недостаточный уровень профессиональной подготовки сотрудников туриндустрии (2,8 балла). Как представляется, пути решения большинства из указанных проблем находятся в компетенции региональных и государственных властей, задающих вектор развития экономики, а также имеющих арсенал инструментов стимулирования звеньев социальной и туристской сфер государства и региона, являющихся наиболее уязвимыми в данном контексте.

Высокие оценки природных и культурных ресурсов региона и их приоритетное влияние на общую его конкурентоспособность позволяют выдвинуть предположение о том, что в основе укрепления и повышения конкурентоспособности туризма Иркутской области должен лежать принцип «зеленой» экономики: «...экономически выгодно то, что экологически безопасно» [7, с. 9]. Как ожидается, это позволит не только усилить положительный эфффект от использования природного и культурного потенциала, воздействующий на конкурентоспособность туризма региона, но и решить столь серьезную для Иркутской области проблему, как низкая устойчивость окружающей среды $(2,1$ балла из 5,0 возможных по результатам оценки конкурентоспособности).

Заключение. Разработанный агрегированный показатель может применяться для получения комплексной объективной оценки уровня конкурентоспособности любого регионального туристского рынка ввиду многогранности используемых элементов оценки, а также универсальности и доступности применяемых методов сбора и обработки данных.

Полученные в ходе оценки конкурентоспособности регионального туризма результаты позволяют разрабатывать своевременные и эффрективные стратегические решения не только в сорере туризма, но и в других общественных сорерах региона, зависимых от туризма и в свою очередь влияющих на него, что в совокупности повышает общее благосостояние исследуемого региона.

Представляется, что результаты проведенного исследования внесут существенный вклад в разработку единообразной методики оценки конкурентоспособности регионального туризма, будут полезны как в научном, так и в практическом аспектах.

\section{СПИСОК ИСПОЛЬЗОВАННОЙ ЛИТЕРАТУРЫ}

1. Бухер С. Конкурентоспособность России на глобальном туристическом рынке / С. Бухер / / Экономика региона. - 2016. — № 1 (12). - C. 240-250. — DOI: 10.17059/2016-1-18.

2. Croitory M. Tourism Competitiveness Index - An Empirical Analysis Romania vs. Bulgari / M. Croitory // Theoretical and Applied Economics. - 2011. — № 9 (562). - P. 155-172.

3. Narkūnienè R. Eastern Aukštaitija region tourism competitiveness analysis / R. Narkūnienè // Agricultural bulletin of Stavropol Region. - 2016. - № 1 (21)/1. - P. 4-8.

4. Trisnawati R. Analysis of the competitiveness tourism industries incising the local economy (The Comparative Study Analysis of the Competitiveness Tourism between Surakarta and Yoguakarta) [Electronic resourse] / R. Trisnawati // Economic Journal of Emerging Markets. - 2008. - № 2 (13). - Mode of access: https://docviewer.yandex. $\mathrm{ru} /$ ?url=http\%3A\%2F\%2Fwww.journal.uii. ac.id\%2Findex.php\%2FJEP\%2Farticle\%2Fdownload\%2F489\%2F403\&na $\mathrm{me}=403 \&$ lang $=\mathrm{en} \& \mathrm{c}=58 \mathrm{bd} 1 \mathrm{dcb} 2 \mathrm{f} 28 \&$ page $=1$.

5. Ласси М. Ю. Анализ подходов к оценке конкурентоспособности регионального туризма в России / М. Ю. Ласси / / Baikal Research Journal. - 2017. - Т. 8, № 2. — DOI: 10.17150/2411-6262.2017.8(2).24.

6. Ласси М. Ю. Оценка конкурентоспособности регионального рынка туристских услуг: модификация индекса конкурентоспособности туризма [Электронный ресурс] / / Активизация интеллектуального и ресурсного потенциала регионов: новые вызовы для менеджмента компаний : материалы 3-й Всерос. конф., Иркутск, 18 мая 2017 г. / под науч. ред. С. В. Чупрова, Н. Н. Даниленко. - Иркутск : Изд-во БГУ, 2017. - С. 169-175. — Режим доступа: https: / /elibrary.ru/item.asp?id=29019171.

7. Нездойминов С. Г. Туризм в условиях перехода к «зеленой» экономике / С. Г. Нездойминов // Российский журнал экотуризма. - 2013. - № 6. - С. 9-14.

\section{REFERENCES}

1. Bucher Slavomir. Competitiveness of the Russian Federation in the Global Tourism Market. Ekonomika regiona = Economy of Region, 2016, vol. 12, iss. 1, pp. 240-250. DOI: 10.17059/2016-1-18. (In Russian).

2. Croitory M. Tourism Competitiveness Index - An Empirical Analysis Romania vs. Bulgari. Theoretical and Applied Economics, 2011, no. 9 (562), pp. 155-172. 
3. Narkūnienè R. Eastern Aukštaitija Region Tourism Competitiveness Analysis. Agricultural bulletin of Stavropol Region, 2016, no. 1 (21)/1, pp. 4-8.

4. TrisnawatiR. Analysis of the Competitiveness Tourism Industries Incising the Local Economy (The Comparative Study Analysis of the Competitiveness Tourism between Surakarta and Yoguakarta). Economic Journal of Emerging Markets, 2008, no. 2 (13). Available at: https://docviewer.yandex.ru/?url=http\%3A\%2F\%2Fwww.journal.uii.ac.id\%2Findex.php\%2FJEP\%2Farticle\%2Fdownload\%2F489\%2F403\&name=403\&lang=en\&c=58bd1 dcb2f28\&page=1 .

5. Lassi M. Yu. Analysis of Approaches to assessing competitiveness of regional Tourism in Russia. Baikal Research Journal, 2017, vol. 8, no. 2. DOl: 10.17150/2411-6262.2017.8(2).24. (In Russian).

6. Lassi M. Yu. Assessment of Competitiveness of the Regional Market of Tourist Services: Modification of the Index of Competitiveness of Tourism. In Chuprov S. V., Danilenko N. N. (eds). Aktivizatsiya intellektual'nogo i resursnogo potentsiala regionov: novye vyzovy dlya menedzhmenta kompanii. Materialy 3-i Vserossiiskoi konferentsii, Irkutsk, 18 maya 2017 g. [Activation of Intellectual and Resource Potential of Regions: New Challenges for Company Management. Materials of $3^{\text {rd }}$ Russian National Research Conference, Irkutsk, 18 May 2017]. Irkutsk, Baikal State University Publ., 2017, pp. 169-175. Available at: https: / /elibrary.ru/item. asp?id=29019171. (In Russian).

7. Nezdoyminov S. G. Tourism in the Conditions of Transition to «Green» Economy. Rossiiskii zhurnal ekoturizma= Russian Journal of Ecotourism, 2013, no. 6, pp. 9-14. (In Russian).

\section{Информация об авторах}

Даниленко Нина Николаевна - доктор экономических наук, профессор, кафедра менеджмента, маркетинга и сервиса, Байкальский государственный университет, 664003, г. Иркутск, ул. Ленина, 11, e-mail: nina.danilenko@gmail.com.

Ласси Марина Юрьевна - аспирант, кафедра менеджмента, маркетинга и сервиса, Байкальский государственный университет, 664003, г. Иркутск, ул. Ленина, 11, e-mail: marina_lassi92@mail.ru.

\section{Для цитирования}

Даниленко Н. Н. Апробация модифицированного (агрегированного) показателя оценки конкурентоспособности регионального туризма (на примере Иркутской области) / Н.Н.Даниленко, М.Ю.Ласси // Известия Байкальского государственного университета. - 2017. - T. 27, № 4. - C. 505-514. - DOI: $10.17150 / 2500-2759.2017 .27(4) .505-514$.

\section{Authors}

Nina N. Danilenko - PhD in Economics, Professor, the Management, Marketing and Service Department, Baikal State University, 11 Lenin St., 664003, Irkutsk, Russian Federation, e-mail: nina.danilenko@gmail.com.

Marina Yu. Lassi - PhD Student, the Management, Marketing and Service Department, Baikal State University, 11 Lenin St., 664003, Irkutsk, Russian Federation; e-mail: marina_lassi92@mail.ru.

\section{For citation}

Danilenko N. N., Lassi M. Yu. Testing of the Modified (Aggregate) Indicator of Assessment of Regional Tourism Competitiveness (Case Study of Irkutsk Oblast). Izvestiya Baykal'skogo gosudarstvennogo universiteta $=$ Bulletin of Baikal State University, 2017, vol. 27, no. 4, pp. 505-514. DOI: 10.17150/25002759.2017.27(4).505-514. (In Russian). 